\title{
Introduction of DMPA in public health facilities of Uttar Pradesh and Rajasthan: An evaluation
}

\author{
M.E. Khan \\ Population Council \\ Anvita Dixit \\ Population Council \\ Jaleel Ahmad \\ Population Council \\ G. Pillai
}

Follow this and additional works at: https://knowledgecommons.popcouncil.org/departments_sbsr-rh

Part of the Demography, Population, and Ecology Commons, Family, Life Course, and Society Commons, International Public Health Commons, and the Women's Health Commons How does access to this work benefit you? Let us know!

\section{Recommended Citation}

Khan, M.E., Anvita Dixit, Jaleel Ahmad, and G. Pillai. 2015. "Introduction of DMPA in public health facilities of Uttar Pradesh and Rajasthan: An evaluation," Project brief. New Delhi: Population Council. 


\section{BACKGROUND}

India is committed to achieving the goals of Family Planning 2020 (FP2020), which, besides substantially increasing new contraceptive users, also demands adopting a rights-based approach and ensuring easy access, choice and good quality services. In the process of increasing contraceptive use. The contraceptive method mix in India has been dominated by female sterilization for a long time. No new contraceptive method has been added to the national family welfare program for decades. The Drugs Controller General of India (DCGI) has approved use of injectable contraceptives in 1994 from the private sector, but still it is not part of the national program.

Recently some initiatives have been taken to make Depo Medroxyprogesterone Acetate (DMPA) available through the public sector in some parts of the country. Two such initiatives that are well known include (a) Urban Health Initiative (UHI) project of FHI360 funded by the Bill and Melinda Gates Foundation (BMGF) which was implemented in public as well as private health facilities of 11 towns of Uttar Pradesh (UP), (b) an initiative taken up by the District Collector of Rajsamand district in Rajasthan, who encouraged district health officials to introduce DMPA in all rural public health facilities in the district like Community Health Centers (CHCs), Primary Health Centers (PHCs) and some of the active Subcente Rs.

The public facilities in UP that participated in the UHI initiative included DMPA while counseling FP clients on the various contraceptive methods available in the facility. The counselors and doctors were oriented by UHI on DMPA. The facilities did not stock DMPA but it was prescribed to women who desired to take DMPA and if she came back with the injection the doctor or the public health nurse of the facility administrated it. The community mobilization of women living in poor localities and slums was done by local Non-Governmental
Organizations (NGOs) partnering with $\mathrm{UHI}$ in educational and motivational effort for adopting contraceptive methods. The NGOs had hired peer educators, each of them responsible for two thousand population, to promote contraceptives among couples in reproductive age. The NGO, Janani, partnered with UHI, organized fixed day clinics at selected spots, where a doctor and a public health nurse provided the services.

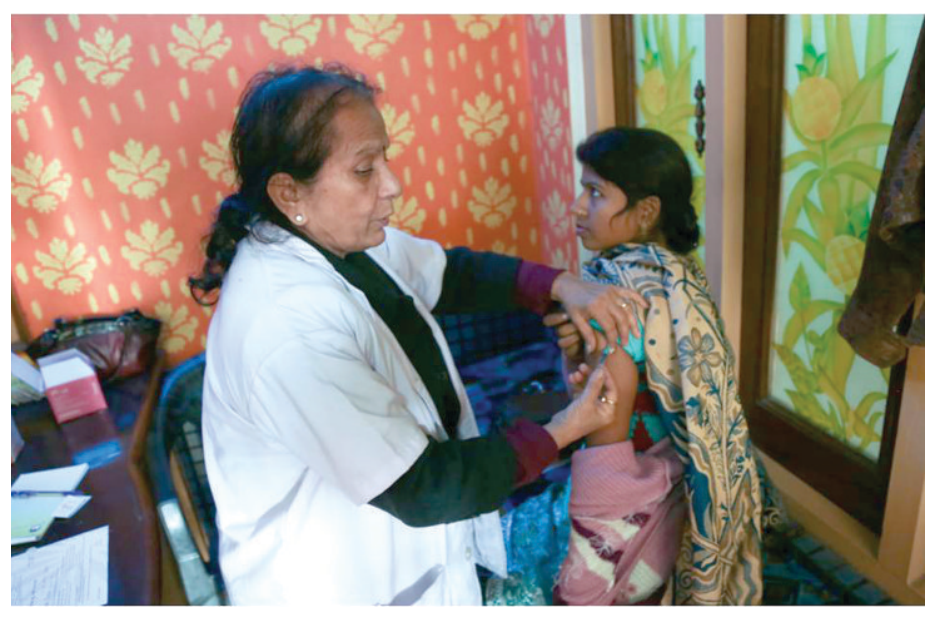

In Rajsamand district, before introducing DMPA, all the doctors and Lady Health Visitors/Auxiliary Nurse Midwifes/ Public Health Nurses (LHVs/ANMs/PHNs) were trained at the district headquarter by district officials and a consultant form Population Health Services India (PHSI), the social marketing agency and promoter of Khushi brand of DMPA. The LHVs gave half-day orientation to Accredited Social Health Activists (ASHAs) on DMPA. The district authorities use their unrestricted fund to purchase DMPA in bulk at a negotiated price of Rs. 28 (US\$ 0.40) per dose from PHSI. The CHCs and PHCs purchase DMPA from the district public store as per their need and charge their clients Rs. 30 (US\$ 0.50) per dose. Thus recovering the unrestricted fund for continued purchase of DMPA. Initially DMPA was provided only at CHCs and PHCs and was mostly administrated by LHVs/PHNs. Later, considering the difficulties faced by women in traveling, DMPA

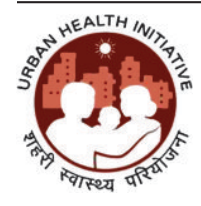

\section{POPULATION 7 COUNCIL}

Ideas. Evidence. Impact. 
was made available on a fixed day of the week at some of the well established Sub-centers and administered by ANM. Initially it was done under the supervision of LHVs of the area.

\section{OBJECTIVE OF THE STUDY}

Present study was undertaken to document these initiatives taken to provide DMPA through public health facilities, which in a way could be taken as feasibility study or initial phase of introducing DMPA in the public sector.

\section{STUDY DESIGN}

A multistage sampling procedure was followed and total of 624 DMPA ever users, 316 from three cities of UP (Allahabad, Lucknow and Aligarh) and 308 from rural areas of Rajsamand district were interviewed with informed consent obtained from each of the participants. The sample was sufficient to provide a statistical valid estimate of responses on the subject. Besides, in-depth interviews were also conducted with nine women to get their perspectives on using DMPA. To get previdus perspectives 38 doctors and 58 paramedics

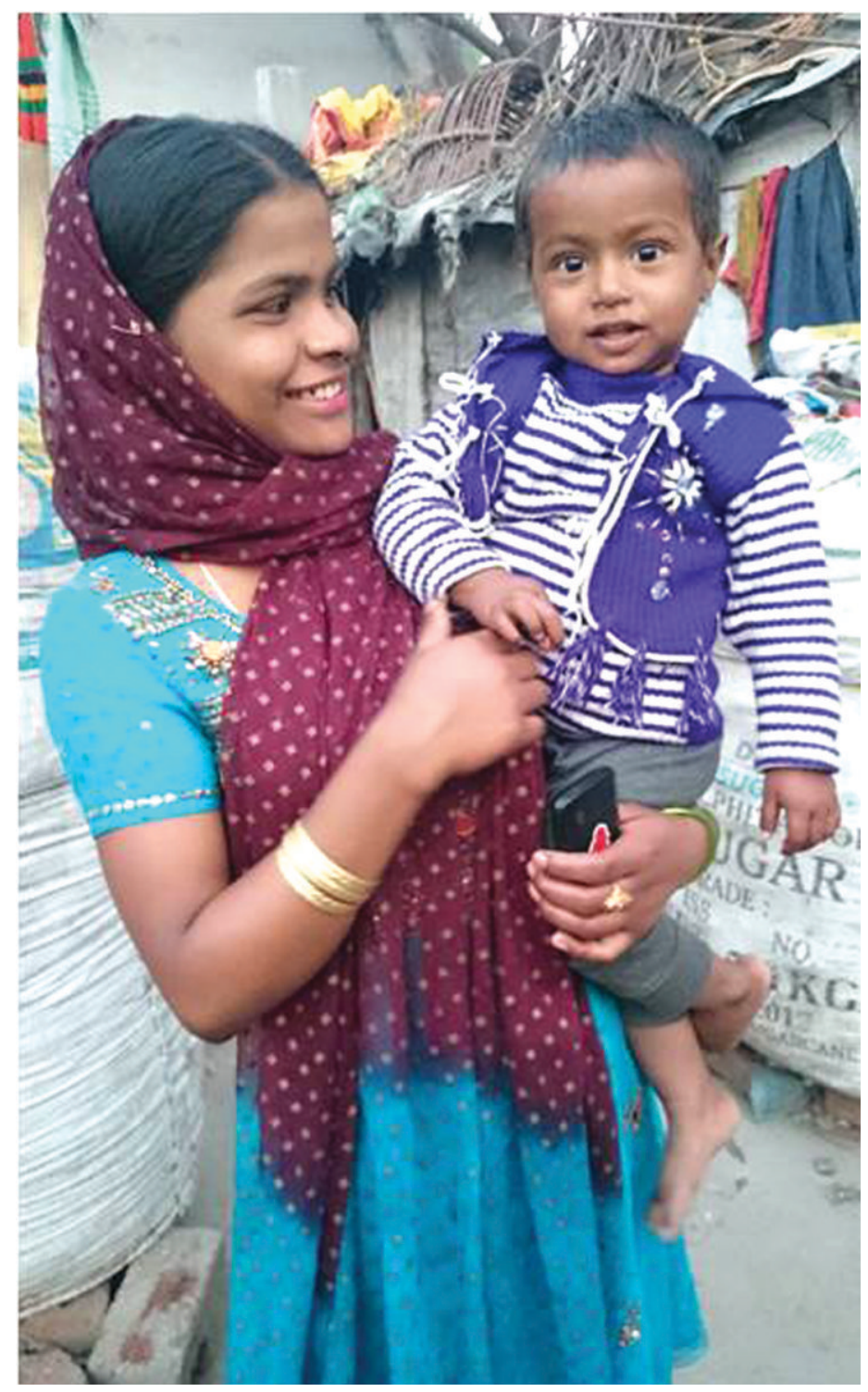

(LHVs/Nurses/ ANMs) from 21 public health facilities of Rajsamand and 15 public health facilities of UP were also interviewed. Additionally, 55 CHWs (33 ASHAs from Rajsamand and 22 peer educators/counselors from UP) were also interviewed.

\section{KEY FINDINGS}

The study revealed that young married women (mean age of 27 years) were using DMPA for spacing births. The reasons for women to choose DMPA over other methods are given in Table 1. About 21 percent women had adopted DMPA after first child and 18 percent did not have a son. It is perhaps because of increased access to additional and long acting spacing method besides IUCD. In the Indian family planning program spacing methods were less promoted than limiting methods as indicated by a low use of IUD and other temporary methods compared to female sterilization. Use of DMPA for spacing births was more in Rajsamand than UP. This is partly because, in Rajsamand DMPA was suggested for spacing while sterilization was suggested to those women who have achieved their desired family size.

\begin{tabular}{|c|c|c|c|}
\hline Reasons & UP & Rajsamand & Total \\
\hline Private \& confidential & 22 & 21 & 21 \\
\hline Nothing to be done daily & 45 & 63 & 54 \\
\hline Easy to use & 39 & 27 & 33 \\
\hline Easily available & 10 & 16 & 13 \\
\hline Effective/reliable/safe & 31 & 30 & 30 \\
\hline Peer educator/friends advice & 40 & 3 & 22 \\
\hline Doctors advised & 5 & 0 & 3 \\
\hline Affordable & 5 & 7 & 6 \\
\hline Other & 12 & 22 & 17 \\
\hline Total (N) & 316 & 308 & 624 \\
\hline
\end{tabular}

*Multiple responses, add up to more than 100.

The following gives a typical quote that was mentioned by several users revealing factors influencing decision to use DMPA.

"I used to forget to take pills. I heard that condom remains inside. So I decided to try injection. The advantage of injection is that after taking it you need not take anything for three months. Injection suits me. The other advantage is that nobody knows about it." (Woman, 24 years, 3 children, 2 doses, Aligarh, UP)

The study shows that overall women as well as other stakeholders had positive opinion about DMPA. Out of the 624 ever users of DMPA interviewed, about 31 percent were current use Rs. Discontinuation was high because of side 


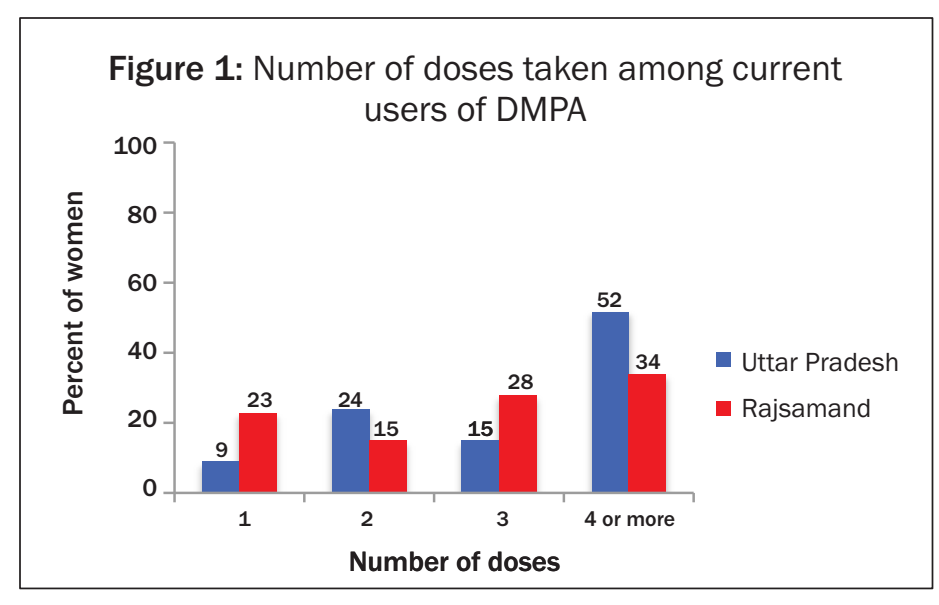

effects. Analysis revealed that discontinuation by second dose was more than 50 percent both in UP and Rajsamand. The study also revealed that among the current users of DMPA, 41 percent (and 13 percent among 624 ever user) had taken four or more doses. The corresponding figure (Figure 1) was 52 percent in UP and 34 percent in Rajsamand.

This is perhaps because of better follow up of first and second dose acceptors of DMPA were motivated by peer educators in UP than ASHAs in Rajsamand. The helpline, called 'Careline', operated by Abt Associates also counselled women, which encouraged them to continue using DMPA (Figure 2).

"I did not find any major problem except that my periods have been stopped and I gain weight." (Woman, 24 years, 2 children, 6 doses, Aligarh, UP)

“Those women who don't have any problems from Depo and those who want to space births take 3 or more doses. But women who face side effects or their husbands find out, or they want more children stop using it." (ASHA, Rajsamand, Rajasthan)

Figure 2 shows most women believed that DMPA is a safe (75 to 80 percent) and effective contraceptive method (90 percent in both study sites). They also believed that DMPA is a good long acting contraceptive method (about 80 percent in the two sites) for spacing births. Women chose DMPA over other spacing methods as it saves them from daily administration of a contraceptive and once taken they do not have to worry about protection for three months. The knowledge of interval between two doses was universal. About half of the women had knowledge about the grace period if they missed their due date. One-third women (27 percent in UP and 33 percent in Rajsamand) did not know how long DMPA could be used continuously. About half the women did not know about return of fertility after discontinuation.

Quality of services was generally good. At all service delivery points in both study sites women were given options of different contraceptive methods to choose from and provider bias towards DMPA was not found. However, in UP, where the peer educators were getting incentive for motivating IUD, DMPA and sterilization, these methods were mentioned more frequently during counseling than other methods.
"Peer educator has told me about all the methods, Copper T, pills, condom" (Woman, 23 years, 3 children, 15 doses, Allahabad, UP).

It is important however to note that about half the women were not told about the side effects indicating improvement in counseling.

Figure 2: Women's knowledge and beliefs on DMPA

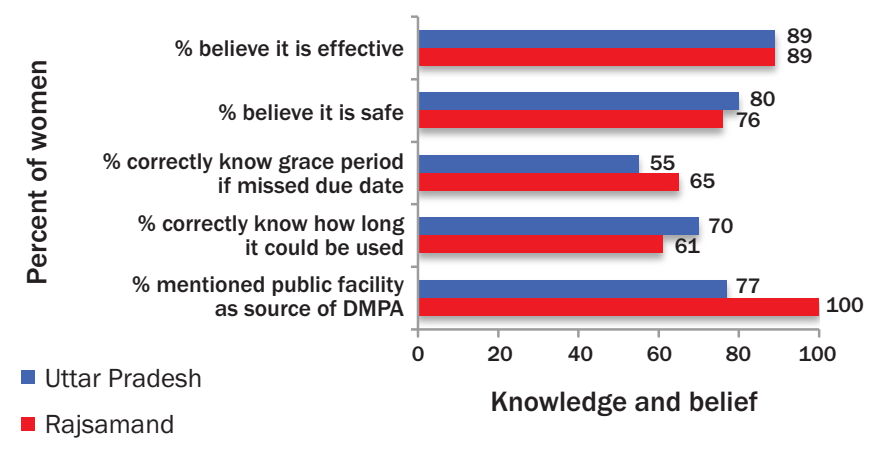

Cost was an issue for more than half of the women, particularly for those women who faced side effects. In some cases cost of treatment from side effects was more than the DMPA. In Rajsamand, cost of the DMPA was lower (Rs. 30, US\$ 0.50) than UP (Rs. 55 to 65 , US\$ 0.90 to 1 ) and majority of the women felt that it could be affordable to most women in their community. The study revealed that in Rajsamand, current price of DMPA i.e. Rs. 30 was acceptable to 92 percent of the women so they expressed their willingness to pay for DMPA. About 73 percent of all the women interviewed felt that up to Rs. 40 , US\$ 0.60 is an acceptable price. More than half of the participants said that they would not be able to pay if the price of DMPA is more than Rs. 65. Therefore, increasing the price beyond Rs. 65 could lead to drastic decline in DMPA use. A similar analysis for UP revealed that current price (Rs. 55-65) was affordable to most (82\%) and an increase up to Rs. 75, US\$ 1.20 would be manageable for 67 percent of the women. Only about 45 percent felt that they would be willing to pay Rs. 100 , US $\$ 1.60$ or more. Overall, the study indicates that the maximum cost for rural area could be Rs. 40 and in rural poor localities and in urban slum areas it could range between Rs. 90 to 100 (US\$ 1.40 to 1.60).

Figure 3: Quality of counseling and care received by women

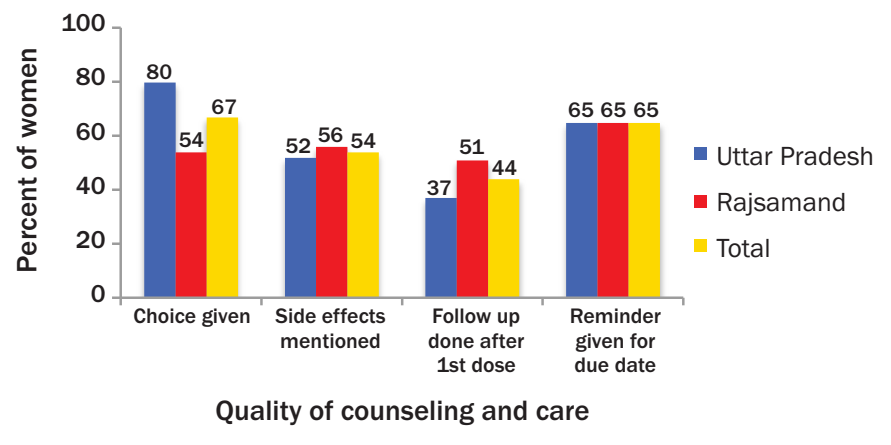




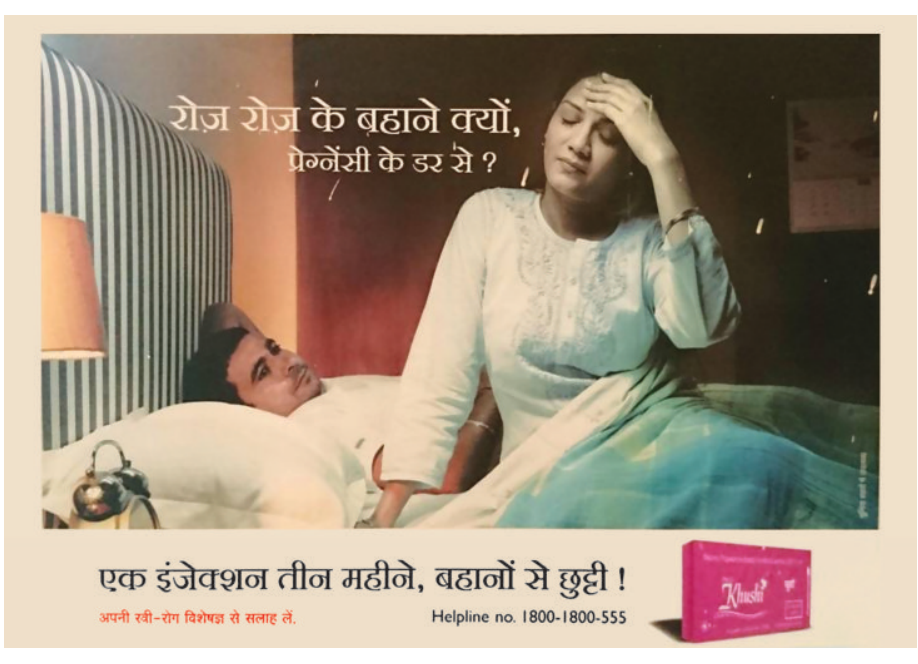

Interviews of the program managers, doctors, paramedics, and community health workers showed that just as the beneficiary had expressed, most provide (90 to 95 percent) strongly felt that DMPA has provided a good additional contraceptive choice to women. Two-third of doctors and paramedics strongly supported that DMPA should be included in the national family welfare program because it is long acting method and once given women do not have to worry for three months (53 percent doctors and 74 percent paramedics), besides they felt that DMPA is safe (25 to 30

\section{TABLE 2: Attitudes of doctors and nurses (percent)}

\begin{tabular}{|c|c|c|}
\hline Attitudes & $\begin{array}{l}\text { Doctors } \\
(\mathrm{N}=38)\end{array}$ & $\begin{array}{l}\text { Nurses } \\
(\mathrm{N}=58)\end{array}$ \\
\hline $\begin{array}{l}\text { Agree that DMPA has provided a } \\
\text { good choice }\end{array}$ & 90 & 95 \\
\hline $\begin{array}{l}\text { Strongly recommended to include } \\
\text { in NFWP }\end{array}$ & 66 & 64 \\
\hline \multicolumn{3}{|l|}{ Key reasons to include in NFWP* } \\
\hline Safe to use & 25 & 30 \\
\hline Effective & 13 & 13 \\
\hline Long acting & 53 & 84 \\
\hline Easy to administer/easy to use & 38 & 23 \\
\hline Private \& confidential & 16 & 29 \\
\hline
\end{tabular}

*Multiple responses, add up to more than 100. percent), easily administered (38 percent doctors and 23 percent paramedics), and keeps contraceptive status confidential (17 percent doctors and 29 percent paramedics) (Table 2). Practically all of them were of the view that the existing amount (Rs. 30 in Rajsamand and about Rs. 65 in UP) is affordable.

\section{RECOMMENDATIONS}

- The study shows that acceptability of the DMPA has remained good despite many women reporting side effects. It indicates that DMPA could be introduced safely without serious health consequences in public sector.

- Most stakeholders, doctors, and paramedics including the beneficiary feel that it should be included in the national family welfare program.

- A supportive environment to introduce DMPA in the public sector is needed. It could be created if FOGSI, IMA and similar medical associations are taken into confidence. DMPA will be an additional long acting contraceptive choice to women willing to space between births and do not want to use IUD or other spacing methods.

- At the initial stages government may plan to introduce DMPA at district health facilities and $\mathrm{CHCs}$ and then expand to PHCs and Sub-cente Rs.

- Like in Rajsamand DMPA could be provided at a cost in public sector. A cost of Rs. 30 to 40 in rural area and Rs. 60 to 100 in urban facilities could be charged. Women are willing to pay that if they are made aware of the method and made easily accessible.

- Counseling and follow up are important measures to promote continuation of DMPA use. Women who use 5 to 6 doses may achieve a minimum desired gap of 3 years between two births.

- Presently up to 50 percent women are dropping out after the $2^{\text {nd }}$ dose of DMPA. This indicates that more studies are required on how to reduce discontinuation rate of DMPA due to side effects and other myths about the method.

Suggested citation: Khan, M. E., Dixit, A., Ahmad, J., \& Pillai, G. (2015). Introduction of DMPA in public health facilities of Uttar Pradesh and Rajasthan: An evaluation. Project brief. New Delhi, India: Population Council. 